\title{
Efficacy of a second TNF blocker, when the first one failed, in patients with juvenile idiopathic arthritis (JIA)
}

\author{
A Salmaso*1, A Lurati ${ }^{2}$, I Pontikaki ${ }^{1}, V_{\text {Gerloni }}{ }^{1}$, M Gattinara $^{1}$, B Teruzzi ${ }^{1}$ and \\ F Fantini $^{1}$
}

\begin{abstract}
Address: ${ }^{1}$ Gaetano Pini Institute Chair of Rheumatology, Milan, Italy and ${ }^{2}$ Fornaroli Hospital Rheumatology Unit, Magenta, Italy
\end{abstract}
* Corresponding author

from $15^{\text {th }}$ Paediatric Rheumatology European Society (PreS) Congress

London, UK. 14-17 September 2008

Published: 15 September 2008

Pediatric Rheumatology 2008, 6(Suppl I):P44 doi:I0.II86/I546-0096-6-SI-P44

This abstract is available from: http://www.ped-rheum.com/content/6/SI/P44

(c) 2008 Salmaso et al; licensee BioMed Central Ltd.

\section{Objectives}

To determine the efficacy of a second treatment with a dif-

ferent TNF blocker in JIA when the first one failed.

\section{Methods}

All JIA patients prospectively followed at our Centre, who failed a first TNF blocker and switched to a second one were enrolled. For each patient the DAS, ACR Ped30, ACR20, ACR50 and ACR70 responses were evaluated at baseline and after a period ranging from 3 to 6 months of each treatment.

\section{Results}

Out of 60 JIA patients enrolled, 40 (37 f, $3 \mathrm{~m}$ ) were evaluated: 10 systemic arthritis, 2 persistent oligoarthritis, 11 extended oligoarthritis, 9 RF negative polyarthritis, 4 RF positive polyarthritis, 1 ERA (enthesitis related arthritis), 3 psoriatic arthritis. With a standard Chi square model, we didn't find a significant difference in the ACR and DAS response rates between the first and the second anti TNF treatment $(p>0.1)$. Stratifying the population for the type of the shift (Etanercept to Infliximab/Adalimumab, Infliximab to Etanercept/Adalimumab) we didn't find a significant difference in the ACR and DAS response rates between the first and the second anti TNF treatment ( $p>$ 0.1 ). Our data show that failure of an anti-TNF therapy in patients with JIA does not preclude a response to a second anti-TNF agent of a different class. 